\title{
Fluconazole-Resistant Candida parapsilosis Bloodstream Isolates with Y132F Mutation in ERG11 Gene, South Korea
}

\section{Yong Jun Choi, ${ }^{1}$ Yae-Jean Kim, ${ }^{1}$ Dongeun Yong, Jung-Hyun Byun, Taek Soo Kim, Yun Sil Chang, Min Ji Choi, Seung Ah Byeon, Eun Jeong Won, Soo Hyun Kim, Myung Geun Shin, Jong Hee Shin}

\begin{abstract}
Author affiliations: Chonnam National University Medical School, Gwangju, South Korea (Y.J. Choi, M.J. Choi, S.A. Byeon, E.J. Won, S.H. Kim, M.G. Shin, J.H. Shin); Samsung Medical Center, Sungkyunkwan University School of Medicine, Seoul, South Korea (Y.-J. Kim, Y.S. Chang); Yonsei University College of Medicine, Seoul (D. Yong, J.-H. Byun); Seoul National University Hospital, Seoul (T.S. Kim)
\end{abstract}

DOI: https://doi.org/10.3201/eid2409.180625

We recently observed the emergence of fluconazole-resistant Candida parapsilosis bloodstream isolates harboring a Y132F substitution in Erg11p in South Korea. These Y132F isolates had a higher propensity to cause clonal transmission than other fluconazole-resistant isolates and persisted within hospitals for several years, as revealed by microsatellite typing.

$C$ andida parapsilosis is the second most common species isolated from patients with Candida bloodstream infections (BSIs) in Latin America and eastern Asia $(1,2)$. Although uncommon, fluconazole-resistant $C$. parapsilosis isolates harboring the Y132F substitution in Erg11p (referred to as Y132F isolates) have been reported in Brazil, the United States, and Kuwait (3-6). The precise reason for the emergence of $C$. parapsilosis $\mathrm{Y} 132 \mathrm{~F}$ isolates has yet to be defined; it may be related to selective drug pressure, and the mutation at position 132 may be a hot spot for resistance mediated by ERG11, a gene encoding the azole target (3). Alternatively, C. parapsilosis Y132F isolate emergence may be associated with exogenous clonal transmission (4). We recently observed the emergence and nosocomial spread of Y132F isolates in South Korea. In this study, we report a greater increase in the clonal spread of $C$. parapsilosis $\mathrm{Y} 132 \mathrm{~F}$ BSI isolates than of non-Y132F fluconazole-resistant isolates within hospitals during the past several years.

We assessed the first 47 C. parapsilosis BSI isolates that were fluconazole-resistant ( $\mathrm{MIC} \geq 8 \mathrm{mg} / \mathrm{L}$ ) according to the Clinical and Laboratory Standards Institute (CLSI) species-specific clinical breakpoint $(7,8)$. All 47 isolates

${ }^{1}$ These authors contributed equally to this article. were obtained from multicenter surveillance cultures from 8 university hospitals (A-H) during 2005-2016. For all fluconazole-resistant isolates, we examined genotypic relationships using microsatellite typing. We defined $\geq 2$ isolates with identical genotypes according to microsatellite typing as clonal isolates. We sequenced the ERG11 gene and 3 transcription factor genes: TAC1, which can lead to the upregulation of $C D R ; M R R 1$, which can lead to the upregulation of MDR; and UPC2, which can lead to the upregulation of ERG11 (5); we compared the results with those of 20 fluconazole-susceptible (MIC $0.5-2 \mathrm{mg} / \mathrm{L}$ ) isolates. This study was approved by the Institutional Review Board of Chonnam National University Hospital (IRB CNUH-2014-290).

Of the 47 C. parapsilosis fluconazole-resistant isolates, $30(63.8 \%)$ had the Y132F substitution in Erg11p; however, none of the 20 fluconazole-susceptible isolates had the Y132F mutation in ERG11. Recently, $31 \%-57 \%$ of fluconazole-resistant $C$. parapsilosis isolates from different parts of the world were reported to be $\mathrm{Y} 132 \mathrm{~F}$ isolates, but the Y132F mutation was absent in all fluconazole-susceptible isolates (3-6). These data confirm that a Y132F substitution in Erg11p is the predominant fluconazole resistance mechanism for $C$. parapsilosis worldwide.

Microsatellite typing revealed that 4 clonal $\mathrm{Y} 132 \mathrm{~F}$ isolates (M1-4) were persistently recovered in 2 hospitals (A and B) over a period of 3-7 years, and the proportion of clonal isolates was much higher in Y132F isolates $(86.7 \%, 26 / 30)$ than in non-Y132F fluconazole-resistant isolates $(11.8 \%, 2 / 17)$ (Table). In a previous microsatellite study from a US surveillance study by Grossman et al. (4), no hospital specificity was detected among 13 non-Y132F fluconazole-resistant isolates; however, 2 notable clusters of isolates from 17 Y $132 \mathrm{~F}$ isolates were found over 8or 18-month periods. The results obtained in our study and those of Grossman et al. indicate that Y132F isolates may have a higher propensity to cause clonal transmission and persist in particular hospitals than do non-Y132F fluconazole-resistant isolates. The Y132F substitution in Erg11p has also been detected in C. auris isolates from Pakistan (10/16 isolates), India (12/17 isolates), and Venezuela (5/5 isolates); these isolates are strongly associated with clonal transmission (9). Further studies are needed to determine whether the Y132F mutation in Erg11p has a direct effect on clonal transmission of $C$. parapsilosis or C. auris isolates.

Two previous studies conducted in the United States detected the Erg 11p Y132F substitution in combination with the Erg11p R398I substitution in almost all C. parapsilosis BSI isolates $(4,5)$. In addition, no Y132F isolates detected in a US surveillance study contained an MRRI polymorphism, according to MRRI sequence analysis 
Table. Molecular characterization of 47 fluconazole-resistant isolates and 20 fluconazole-susceptible isolates of Candida parapsilosis, South Korea*

\begin{tabular}{|c|c|c|c|c|c|c|c|c|c|}
\hline \multirow{2}{*}{$\begin{array}{l}\text { Microsatellite } \\
\text { genotypes } †\end{array}$} & \multirow[b]{2}{*}{ Hospital } & \multirow{2}{*}{$\begin{array}{c}\text { No. } \\
\text { isolates }\end{array}$} & \multicolumn{2}{|c|}{ MICs, mg/Lł } & \multicolumn{4}{|c|}{ Amino acid substitutions $\S$} & \multirow[b]{2}{*}{ Isolation year (no. patients) } \\
\hline & & & FLC & VRC & Erg11p & Mrr1p & Tac1p & Upc2p & \\
\hline \multicolumn{10}{|c|}{ Fluconazole-resistant with $\mathrm{Y} 132 \mathrm{~F}$ in Erg11p, $\mathrm{n}=30$ isolates } \\
\hline \multirow[t]{2}{*}{ M1 } & A & 8 & $8-32$ & $0.25-0.5$ & Y132F & $\mathrm{K} 177 \mathrm{~N}$ & & & $\begin{array}{l}2006 \text { (1), } 2009 \text { (1), } 2010 \text { (2), } \\
2011 \text { (2), } 2012 \text { (1), } 2013(1)\end{array}$ \\
\hline & $\mathrm{B}$ & 3 & $16-32$ & 0.5 & Y132F & $\mathrm{K} 177 \mathrm{~N}$ & & & $2012(2), 2013(1)$ \\
\hline M2 & A & 10 & $8-32$ & $0.125-0.5$ & Y132F & K177N & & & $2012(1), 2016(9)$ \\
\hline M3 & A & 3 & $8-16$ & 0.25 & Y132F & $\begin{array}{l}\text { K177N, } \\
\text { Q1053* }\end{array}$ & & & 2007 (1), $2011(1), 2012$ (1) \\
\hline M4 & $A$ & 2 & $8->64$ & $0.5-4$ & Y132F & $\mathrm{K} 177 \mathrm{~N}$ & & & 2013 (1), 2016 (1) \\
\hline M5 & A & 1 & 32 & 0.25 & Y132F & K177N & & & $2012(1)$ \\
\hline M6 & $A$ & 1 & 8 & 0.5 & Y132F & $\mathrm{K} 177 \mathrm{~N}$ & & & 2013 (1) \\
\hline M7 & $A$ & 1 & 8 & 0.25 & Y132F & $\mathrm{K} 177 \mathrm{~N}$ & & & 2016 (1) \\
\hline M8 & $\mathrm{C}$ & 1 & 64 & 2 & Y132F & & & & 2016 (1) \\
\hline \multicolumn{10}{|c|}{ Other fluconazole-resistant, $n=17$ isolates } \\
\hline M9 & D & 2 & $>64$ & 1 & & G583R & & & 2007 (1), 2009 (1) \\
\hline M10 & $\mathrm{E}$ & 1 & 16 & 0.5 & R398I & & L877P & & $2005(1)$ \\
\hline M11 & A & 1 & 8 & 0.25 & & & & & $2006(1)$ \\
\hline M12 & $E$ & 1 & 8 & 0.25 & R398I & & L877P & & 2011 (1) \\
\hline M13 & $\mathrm{F}$ & 1 & 16 & 0.06 & R398I & & L877P & & 2011 (1) \\
\hline M14 & $E$ & 1 & 8 & 0.125 & R398I & & L877P & & 2012 (1) \\
\hline M15 & $\mathrm{G}$ & 1 & 8 & 0.125 & R398I & & L877P & & 2012 (1) \\
\hline M16 & $\mathrm{G}$ & 1 & 8 & 0.06 & R398I & & L877P & & 2012 (1) \\
\hline M17 & $E$ & 1 & 8 & 0.125 & & & N900D & & 2012 (1) \\
\hline M18 & $\mathrm{C}$ & 1 & 8 & 0.125 & R398I & P250S & L877P & & 2012 (1) \\
\hline M19 & C & 1 & 8 & 0.25 & R398I & S1081P & L877P & & 2012 (1) \\
\hline M2O & $\mathrm{D}$ & 1 & 8 & 0.125 & R398I & & & D394N & 2012 (1) \\
\hline M21 & $\mathrm{E}$ & 1 & 32 & 0.5 & R398I & P295R & L877P & & 2015 (1) \\
\hline M22 & $\mathrm{E}$ & 1 & 16 & 0.125 & R398I & & & & 2015 (1) \\
\hline M23 & $\bar{H}$ & 1 & 32 & 0.125 & $\mathrm{~K} 128 \mathrm{~N}$ & W872C & & & 2015 (1) \\
\hline M24 & $E$ & 1 & 16 & 0.25 & & G927D & & & 2016 (1) \\
\hline \multicolumn{10}{|c|}{ Fluconazole-susceptible controls } \\
\hline M3 & A & 1 & 1 & 0.03 & & $\begin{array}{l}\text { K177N, } \\
\text { Q1053* }\end{array}$ & & & $2010(1)$ \\
\hline M25 & $\mathrm{C}$ & 2 & 0.5 & 0.03 & R398I & & & & $2012(2)$ \\
\hline M26 & $\mathrm{F}$ & 2 & 0.5 & $0.03-0.06$ & & & R208G & & $2012(1), 2013(1)$ \\
\hline M27 & A & 1 & 2 & 0.06 & & & & & $2010(1)$ \\
\hline M28 & A & 1 & 0.5 & 0.03 & & $\begin{array}{l}\text { K177N, } \\
\text { Q1053* }\end{array}$ & & & $2011(1)$ \\
\hline M29 & $A$ & 1 & 1 & 0.06 & & & L877P & & 2011 (1) \\
\hline M30 & $A$ & 1 & 1 & 0.03 & & & R208G & & 2012 (1) \\
\hline M31 & $A$ & 1 & 0.5 & 0.03 & & & R208G & & 2012 (1) \\
\hline M32 & $E$ & 1 & 2 & 0.03 & & & & & 2012 (1) \\
\hline M33 & G & 1 & 0.5 & 0.03 & & & R208G & & 2012 (1) \\
\hline M34 & G & 1 & 0.5 & 0.03 & & & & & 2012 (1) \\
\hline M35 & $A$ & 1 & 0.5 & 0.03 & & & R208G & & 2013 (1) \\
\hline M36 & $A$ & 1 & 1 & 0.06 & R398I & & & D394N & 2013 (1) \\
\hline M37 & $A$ & 1 & 0.5 & 0.03 & R398I & & & & 2013 (1) \\
\hline M38 & $D$ & 1 & 0.5 & 0.06 & R398I & & & & 2014 (1) \\
\hline M39 & $\mathrm{D}$ & 1 & 0.5 & 0.06 & & & R208G & & 2014 (1) \\
\hline M40 & $E$ & 1 & 0.5 & 0.03 & & & R208G & & 2015 (1) \\
\hline M41 & A & 1 & 1 & 0.03 & R398I & & L877P & & 2015 (1) \\
\hline \multicolumn{10}{|c|}{ 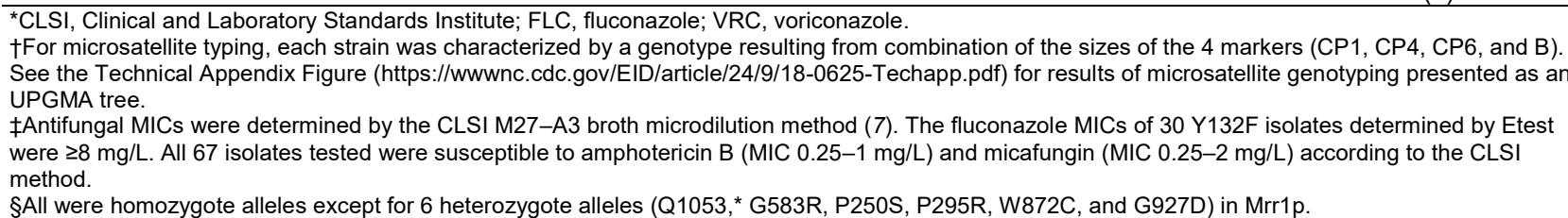 } \\
\hline
\end{tabular}

results (4). However, a single Y132F substitution in Erg11p was found in all 30 fluconazole-resistant isolates from South Korea hospitals. The same K177N substitution in Mrrlp was found in all Y132F isolates except 1; none of the Y132F isolates showed missense mutations in Tac1p or
Upc2p (Table). Taken together, these findings demonstrate low genetic diversity among Y132F isolates from the same country (the United States or South Korea).

In our study, $76.7 \%(23 / 30)$ of patients with Y132F isolates had no antifungal exposure within 30 days before 
candidemia detection, and their clonal transmission was not detected by routine hospital surveillance, partly because more than half of the patient hospitalizations did not overlap. These findings indicate that clonal $\mathrm{Y} 132 \mathrm{~F}$ isolates may be dormant over long periods and can survive and persist outside their host on hospital environmental surfaces, which may be similar to the behavior of $C$. auris (10). Although our study was limited by the relatively low number of isolates, our data suggest that $C$. parapsilosis $\mathrm{Y} 132 \mathrm{~F}$ isolates should be identified in clinical microbiology laboratories to prevent further clonal transmission of BSI caused by $\mathrm{Y} 132 \mathrm{~F}$ isolates.

This research was supported by the Basic Science Research Program through the National Research Foundation of Korea funded by the Ministry of Education

(NRF-2016R1A2B4008181).

\section{About the Author}

Dr. Y.J. Choi is a clinical pathologist at Chonnam National University Hospital, Gwangju, South Korea. His current research interest is molecular epidemiology of fungal infections.

\section{Reference}

1. Pfaller MA, Jones RN, Doern GV, Sader HS, Messer SA, Houston A, et al.; The SENTRY Participant Group. Bloodstream infections due to Candida species: SENTRY antimicrobial surveillance program in North America and Latin America, 1997-1998. Antimicrob Agents Chemother. 2000;44:747-51. http://dx.doi.org/10.1128/AAC.44.3.747-751.2000

2. Sandven P. Epidemiology of candidemia. Rev Iberoam Micol. 2000;17:73-81.

3. Souza AC, Fuchs BB, Pinhati HM, Siqueira RA, Hagen F, Meis JF, et al. Candida parapsilosis resistance to fluconazole: molecular mechanisms and in vivo impact in infected Galleria mellonella larvae. Antimicrob Agents Chemother. 2015;59:6581-7. http://dx.doi.org/10.1128/AAC.01177-15

4. Grossman NT, Pham CD, Cleveland AA, Lockhart SR Molecular mechanisms of fluconazole resistance in Candida parapsilosis isolates from a U.S. surveillance system. Antimicrob Agents Chemother. 2015;59:1030-7. http://dx.doi.org/10.1128/ AAC.04613-14

5. Berkow EL, Manigaba K, Parker JE, Barker KS, Kelly SL, Rogers PD. Multidrug transporters and alterations in sterol biosynthesis contribute to azole antifungal resistance in Candida parapsilosis. Antimicrob Agents Chemother. 2015;59:5942-50. http://dx.doi.org/10.1128/AAC.01358-15

6. Asadzadeh M, Ahmad S, Al-Sweih N, Khan Z. Epidemiology and molecular basis of resistance to fluconazole among clinical Candida parapsilosis isolates in Kuwait. Microb Drug Resist. 2017;23:966-72. http://dx.doi.org/10.1089/ mdr.2016.0336

7. Clinical and Laboratory Standards Institute. Reference method for broth dilution antifungal susceptibility testing of yeaststhird edition: approved standard (M27-A3). Wayne (PA): The Institute; 2008

8. Clinical and Laboratory Standards Institute. Reference method for broth dilution antifungal susceptibility testing of yeasts: fourth informational supplement (M27-S4). Wayne (PA): The Institute; 2012.
9. Lockhart SR, Etienne KA, Vallabhaneni S, Farooqi J, Chowdhary A, Govender NP, et al. Simultaneous emergence of multidrug-resistant Candida auris on 3 continents confirmed by whole-genome sequencing and epidemiological analyses. Clin Infect Dis. 2017;64:134-40. http://dx.doi.org/10.1093/cid/ciw691

10. Welsh RM, Bentz ML, Shams A, Houston H, Lyons A, Rose LJ, et al. Survival, persistence, and isolation of the emerging multidrug-resistant pathogenic yeast Candida auris on a plastic health care surface. J Clin Microbiol. 2017;55:2996-3005. http://dx.doi.org/10.1128/JCM.00921-17

Address for correspondence: Jong Hee Shin, Chonnam National University Medical School, Department of Laboratory Medicine, 42 Jebong-ro, Dong-gu, Gwangju 61469, South Korea; email: shinjh@chonnam.ac.kr

\section{Borrelia miyamotoi Disease in an Immunocompetent Patient, Western Europe}

\author{
Dieuwertje Hoornstra, ${ }^{1}$ Joris Koetsveld, ${ }^{1}$ \\ Hein Sprong, Alexander E. Platonov, \\ Joppe W. Hovius
}

Author affiliations: Academic Medical Center, Amsterdam, the Netherlands (D. Hoornstra, J. Koetsveld, J.W. Hovius); National Institute for Public Health and the Environment, Bilthoven, the Netherlands (H. Sprong); Central Research Institute of Epidemiology, Moscow, Russia (A.E. Platonov)

DOI: https://doi.org/10.3201/eid2409.180806

Borrelia miyamotoi disease is a hard tick-borne relapsing fever illness that occurs across the temperate climate zone. Human B. miyamotoi disease in immunocompetent patients has been described in Russia, North America, and Japan. We describe a case of $B$. miyamotoi disease in an immunocompetent patient in western Europe.

A 72-year-old woman in the Netherlands sought treatment in her third day of fever $\left(\leq 38.6^{\circ} \mathrm{C}\right)$ and reported myalgia, arthralgia, headache, and a $2.5-\mathrm{kg}$ weight loss. Three weeks earlier she had noticed a tick bite after gardening. Several days later, an erythematous lesion appeared, increasing to palm size within 1.5 weeks and dissolving in a similar period. Full medical history was not

${ }^{1}$ These authors contributed equally to this article. 